4. Армстронг М. Практика управления человеческими ресурсами. - 10-е издание / Перев. с англ. - СПб.: Питер, 2010.

5. Гарбер Е.И., Козача В.В. Методика профессиографии. Саратов, 1992.

6. Глазунова Н.И. Система государственного управления. - М.: ЮНИ- ТИ-ДАНА, 2011.

7. Гришковец А.А. Правовое регулирование государственной службы // ЖРП. 1998. №7. М., - С.24-36: Контракт; Инфра-М., 1998

8. Деркач А.А. Основы общей и прикладной акмеологии. М., 1995.Деркач А.А., Зазыкии В.Г., Маркова А.К. Психология развития профессионала: учеб. пособие. М., 2000.

9. Киселев С.Г. Государственная гражданская служба: учеб. пособие. М., 2007.

10. Климов Е.А. Психология профессионала. М., 1996.

11. Понамарева А.Я. Государственное и муниципальное управление, 1997

12. Радченко А.И. Основы государственного и муниципального управления: системный подход / А.И. Радченко. - Ростов н/Д: Ростиздат, 2008.

13. Свирина И. Кадровые технологии в управлении персоналом государственной гражданской службы // Журнал «Власть. - 2014. - № 7.

Толыпина И.В.

\title{
Состав и соотношение стимулирующих элементов оплаты труда госслужащихв
} РФ и зарубежных странах

Белгородский Государственный Наџиональный Исследовательский Университет

(Россия, Белгород)

doi: $10.18411 / l j-31-10-2017-07$

idsp: 000001:lj-31-10-2017-07

Научный руководитель: Олейник Н.Н.

\section{Аннотация}

В данной статье проведен сравнительный анализ структурных элементов оплаты труда государственных служащих зарубежных стран и России. Автором рассмотрены типовые выплаты государственным служащим в международной практике, определены размеры и соотношения между постоянными и переменными частями оплаты. Особое внимание уделено элементам оплаты по результатам, расчету их удельного веса в совокупном размере денежного содержания государственных служащих.Проанализированы текущее состояние и недостатки существующей системы оплаты труда на государственной гражданской службе в Российской Федерации, даны рекомендации по совершенствованию структуры денежного содержания и сближению российской практики с современными моделями стимулирования по результатам.

Ключевые слова: структура оплаты труда, премиальные выплаты, вознаграждения, надбавки, ежемесячные денежные поощрения, должностной оклад, премия

Современный опыт государственного управления требует все более высокой эффективности от государственной службы, разработки и внедрения новых технологий служебной деятельности, оказания государственных услуг, межведомственного взаимодействия. Согласно различным оценкам $[4$, с.15] и социологическим опросам населения [7, с.12], государственный аппарат в настоящее время отличается избыточной бюрократизацией, неэффективностью функционирования, раздутой численностью и длительными сроками согласования и решения вопросов. В последнее время растет число исследований, посвященных проблеме повышения эффективности деятельности государственных служащих и концентрирующихся на вопросах мотивации чиновников к достижению конкретных результатов $[12$, с.25]. Одна из ключевых тем таких исследований - построение системы оплаты труда по результатам (performancerelatedpay) $[15$, c.37] и поиск наиболее эффективных элементов стимулирования в структуре денежного содержания государственных служащих $[10$, с.6]. Международный опыт 
демонстрирует значительное разнообразие применяемых структурных элементов и способов оплаты по результатам в государственном секторе. Наиболее распространенными и типовыми компонентами в структуре оплаты труда государственных служащих в международной практике являются [14, c.18]:

- оклад в соответствии с занимаемой должностью (base salary);

- оклад в соответствии с квалификацией, грейдом, принадлежностью к определенной группе (grade salary);

- надбавки (Ошибка! Закладка не определена.);

- повышающие выплаты (Ошибка! Закладка не определена.increments);

- вознаграждения (Ошибка! Закладка не определена.); - премии (premiums); - бонусы (bonuses).

В отдельных странах существуют свои особенности в структуре оплаты труда государственных служащих - это компоненты денежного содержания, не относящиеся напрямую к перечисленным, но связанные со стимулированием по результатам. К таким компонентам относятся, например, система консолидированных базовых вознаграждений (consolidated basepayawards) и неконсолидированных премий (nonconsolidated bonuses) в Великобритании [24], повышающие процентные ставки к уровню оплаты (ratesfor thejob) в Австралии [9, с.24], система дополнительных поощрительных выплат по результатам (results-based rewards) в Финляндии [13, с.10], плата за дополнительный риск при заключении соглашения о результативности с повышенными обязательствами (pay atrisk) в Канаде [11, с.17] и т.д.

Важными при систематизации многообразия элементов в структуре оплаты труда государственных служащих в зарубежных странах являются их отнесение к постоянной или переменной части оплаты труда, гарантированность или негарантированность их выплаты, а также взаимосвязь с оценкой компетенций, знаний, умений или результативности деятельности. Данные зависимости отражены в табл. 1.

Таблица 1

Основные элементы структурыоплаты труда государственных служаших в зарубежсных станах

\begin{tabular}{|c|c|c|c|}
\hline & $\begin{array}{c}\text { Постоянная } \\
\text { часть оплаты }\end{array}$ & $\begin{array}{c}\text { Переменная } \\
\text { часть оплаты }\end{array}$ & \\
\hline $\begin{array}{c}\text { Выплаты } \\
\text { гарантированы }\end{array}$ & $\begin{array}{c}\text { - оклад в соответствии } \\
\text { с занимаемой должностью } \\
\text { (basesalary) }\end{array}$ & $\begin{array}{c}\text { - оклад в соответствии } \\
\text { с квалификацией, } \\
\text { грейдом, } \\
\text { принадлежностью к } \\
\text { определенной группе } \\
\text { (gradesalary); } \\
\text { - вознаграждения } \\
\text { (rewards); } \\
\text { - } \\
\text { неконсолидированные } \\
\text { премии (non- } \\
\text { consolidatedbonuses) }\end{array}$ & $\begin{array}{c}\text { Оценка } \\
\text { компетенций, } \\
\text { знаний, умений }\end{array}$ \\
\hline $\begin{array}{c}\text { Выплаты } \\
\text { негарантированные }\end{array}$ & $\begin{array}{c}\text { - надбавки (allowances); } \\
\text { - повышающие процентные } \\
\text { ставки к уровню оплаты } \\
\text { (ratesforthejob); } \\
\text { - консолидированные } \\
\text { базовые вознаграждения } \\
\text { (consolidatedbasepayawards) }\end{array}$ & $\begin{array}{c}\text { - повышающие } \\
\text { выплаты } \\
\text { (payincrements); } \\
\text { - премии (premiums); } \\
\text { - бонусы (bonuses);- } \\
\text { дополнительные } \\
\text { поощрительные } \\
\text { выплаты по } \\
\text { результатам (results- } \\
\text { basedrewards); } \\
\text { - платазаpиск } \\
\text { (рау at risk) }\end{array}$ & $\begin{array}{c}\text { Оценка } \\
\text { результативности } \\
\text { деятельности }\end{array}$ \\
\hline
\end{tabular}


На основе данной систематизации можно выделить следующие три части в структуре оплаты труда государственных служащих в зарубежных странах:

- постоянная часть оплаты, не зависящая от результативности деятельности государственных служащих (1-й и 3-й квадранты);

- условно-переменная часть оплаты, зависящая от компетенций, знаний, умений и частично результативности деятельности государственных служащих (2-й квадрант);

- переменная часть оплаты, в большой степени зависящая от результативности деятельности государственных служащих (4-й квадрант).

Медианные значения соотношений постоянной, условно-переменной и переменной частей в структуре оплаты труда государственных служащих в различных странах приведены на рис. 1.

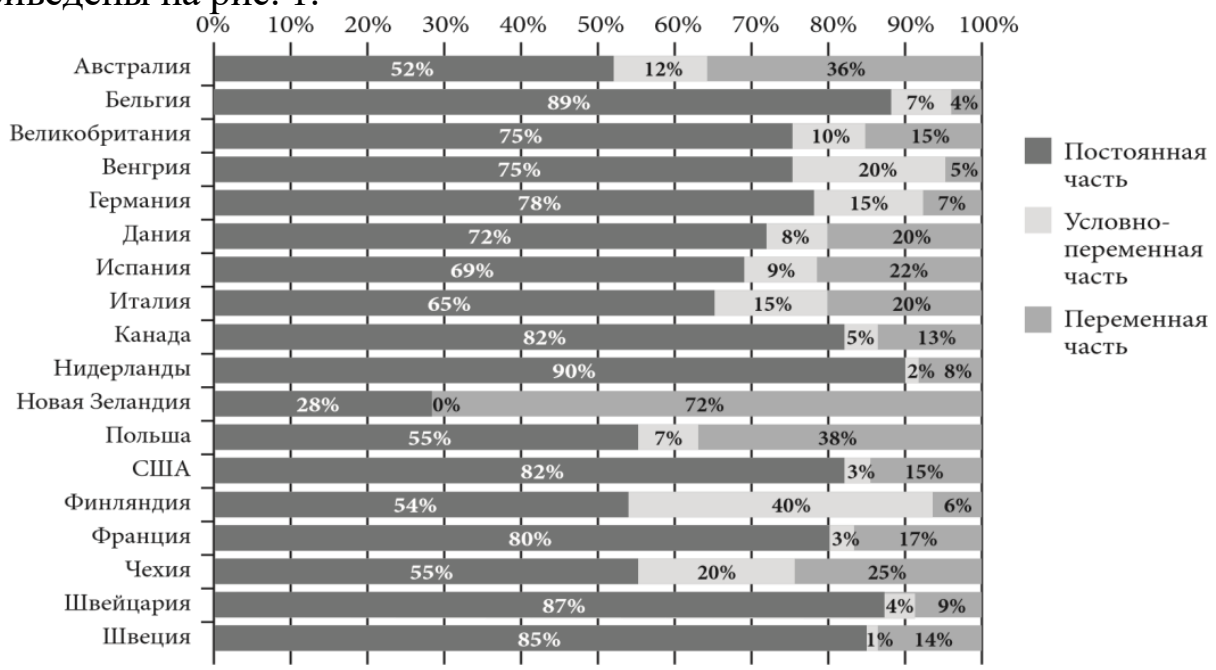

Рис.1 Соотношения постоянной, условно-переменной и переменной частей в структуре оплаты труда государственных служащих в различных странах

Средние значения условно-переменной и переменной частей в структуре оплаты труда государственных служащих составляют соответственно 10 и 19\%. Следует отметить, что дифференциация процентного отношения результативной части оплаты труда к остальной в зарубежных странах отличается неоднородностью - от 4 до 72\%, наиболее часто на практике встречается соотношение в распределении постоянных и премиальных выплат как 70 - 10 - 20\% (фиксированный оклад - надбавки - премии по результатам).

Анализ международного опыта показывает, что наличие в структуре оплаты труда государственных служащих премиальных выплат, непосредственно связанных с результатами деятельности, имеет высокое стимулирующее значение, и чем большей и менее гарантированной является доля элементов результативной оплаты, тем в большей степени работа государственного служащего направлена на выполнение поставленных целей и задач, достижение установленных показателей результативности.Использование международного опыта может быть востребовано при проведении преобразований на государственной службе в Российской Федерации. Совершенствование системы оплаты труда государственных служащих является в настоящее время крайне актуальным вопросом, что находит отражение в принимаемых нормативных правовых актах. Одно из основных мероприятий Федеральной программы «Реформирование и развитие системы государственной службы Российской Федерации (2009-2013 годы)» [2] - оптимизация порядка оплаты труда государственных служащих, внедрение принципов оплаты по результатам. Основными направлениями совершенствования системы государственного управления согласно недавнему Указу Президента Российской Федерации от 7 мая 2012 г. 
№ 601 «Об основных направлениях совершенствования системы государственного управления» являются:

- совершенствование системы оплаты труда государственных гражданских служащих;

- установление особого порядка оплаты труда государственных гражданских служащих в зависимости от достижения показателей результативности профессиональной служебной деятельности, а также единого подхода к осуществлению выплаты государственным гражданским служащим премий за выполнение особо важных и сложных заданий по результатам работы;

- увеличение в оплате труда государственных гражданских служащих доли, обусловленной реальной эффективностью их работы.

Структура оплаты труда гражданских служащих в Российской Федерации регламентируется Федеральным законом от 27 июля 2004 г. № 79-Фз «О государственной гражданской службе Российской Федерации» [1], в соответствии с которым денежное содержание гражданского служащего состоит из следующих элементов: - должностного оклада;

- оклада за классный чин;

- надбавки за выслугу лет;

- надбавки за особые условия гражданской службы;

- надбавки за работу со сведениями, составляющими государственную тайну;

- ежемесячного денежного поощрения;

- выплаты при предоставлении ежегодного оплачиваемого отпуска;

- материальной помощи;

- премии за выполнение особо важных и сложных заданий.

По аналогии с проанализированным международным опытом можно дифференцировать структуру выплат, составляющих денежное содержание, на элементы, образующие постоянную и переменную части оплаты, и определить их взаимосвязь с результативностью деятельности государственных гражданских служащих, все выплаты в структуре денежного содержания государственных гражданских служащих составляют постоянную часть, к условно-переменной и переменной частям относится по одной выплате.

Медианные значения соотношений постоянной, условно-переменной и переменной частей в структуре оплаты труда государственных служащих в Российской Федерации приведены на рис. 2.

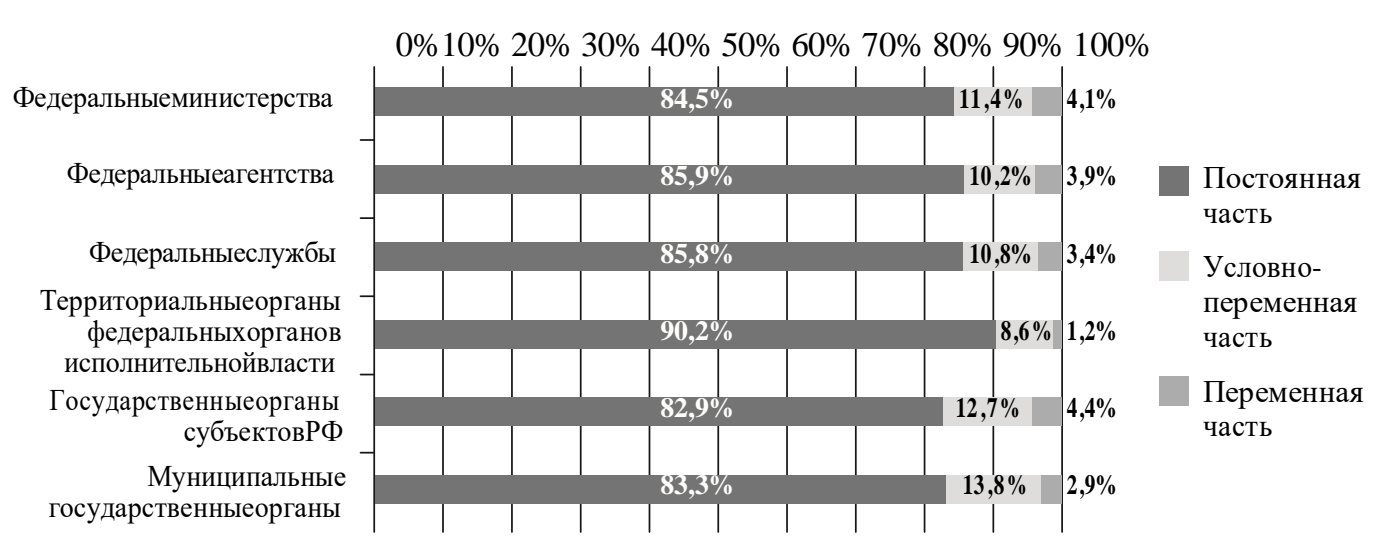

Рис.2. Соотношения постоянной, условно-переменной и переменнойчастей в структуре оплать труда государственных гражданскихслужащиих в Российской Федераџии

Средние значения условно-переменной и переменной частей в структуре оплаты труда государственных гражданских служащих составляют соответственно 11,3 и 3,3\%. Следует отметить, что ни в одной из проанализированных зарубежных стран нет такой 
низкой доли в структуре денежного содержания, приходящейся на премиальную часть, а соотношение 86 - 11 - 3\% (оклад и большинство дополнительных выплат - надбавка за особые условия гражданской службы - премия за выполнение особо важных и сложных заданий) не позволяет осуществлять эффективное стимулирование государственных гражданских служащих. В этой связи следует как можно быстрее осуществить переход к новой системе оплаты труда государственных гражданских служащих. Для совершенствования системы денежного содержания и внедрения элементов оплаты по результатам на государственной гражданской службе в Российской Федерации необходимо:

- включить в должностной оклад все надбавки и дополнительные выплаты, носящие гарантированно-постоянный характер и не используемые для стимулирования государственных гражданских служащих;

- существенно увеличить в структуре денежного содержания долю выплат, направляемых на премирование;

- изменить название и назначение надбавки за особые условия гражданской службы, связав ее с уровнем квалификации и профессионализма государственных гражданских служащих;

- законодательно закрепить новый вид дополнительной выплаты - «премии за результативность профессиональной служебной деятельности».

$$
\text { *** }
$$

1. Федеральный закон от 27.07.2004 г. № 79-Фз «О государственной гражданской службе Российской Федерации».

2. Указ Президента Российской Федерации от 10.03.2009 г. № 261 «О федеральной программе "Реформирование и развитие системы государственной службы Российской Федерации (2009-2013 годы)"》.

3. Указ Президента Российской Федерации от 07.05.2012 г. № 601 «Об основных направлениях совершенствования системы государственного управления».

4. Открытое Правительство. Доклад Президенту Российской Федерации по итогам деятельности Рабочей группы по формированию системы «Открытое правительство», 2012. URL: http://большоеправительство.рф/report/1445/ (дата обращения: 20.09.2017).

5. $\quad$ Росстат. О численности и оплате труда государственных гражданских и муниципальных служащих на $\begin{array}{llllll}\text { региональном уровне в } & \text { I }\end{array}$ http://www.gks.ru/bgd/free/b04_03/IssWWW.exe/Stg/d04/194.htm (дата обращения: 20.09.2017).

6. Росстат. Справка о численности и оплате труда гражданских служащих федеральных государственных органов (центральных аппаратов министерств и ведомств) в I полугодии 2017 года. URL: http://www.gks.ru/bgd/free/b04_03/IssWWW.exe/Stg/d04/plat23.htm (дата обращения: 29.09.2017).

7. Фонд «Общественное мнение». Оценка качества госуслуг. Довольны ли граждане тем, как их обслуживает государство? Опрос «ФОМнибус», репрезентативныйопрос1500 человек, 29.04.2016 г.

8. Alonso P., Lewis G. Public Service Motivation and Job Performance: Evidence from the Federal Sector // American Review of Public Administration. 2010. Vol. 31. № 4. P. 363-381.

9. Australian Public Service Commission. Performance Management Guidance, 2010.

10. Binderkrantz A.S., Christensen J.G. Agency Performance and Executive Pay in Government: An Empirical Test // Journal of Public Administration Research and Theory. 2012. Vol. 22. № 1. P. 31-49.

11. Canada, Privy Council Office, Performance Management Program Guidelines. Deputy Ministers, Associate Deputy Ministers and Individuals Paid in the GX Salary Range. Senior Personnel and Special Projects Secretariat, 2016.

12. Coursey D., Yang K., Pandey S. Public Service Motivation (PSM) and Support for Citizen Participation: A Test of Perry and Vandenabeele's Reformulation of PSM Theory // Public Administration Review. JulyAugust 2014. Vol. 72. № 4. P. 572-581.

13. Finnish Ministry of Labour, Handbook on Performance Management.May, 2014

14. Gene A Brewer; Sally, Coleman Selden; Rex, L Facer II. Individual Conceptions of Public Service Motivation // Public Administration Review. May-June 2011. Vol. 60. № 3. P. 254-264.

15. Kang, Sung-Choon; Yanadori, Yoshio. Adoption and Coverage of PerformanceRelatedPay during Institutional Change:An Integration of Institutional and Agency Theories // The Journal of Management Studies. December 2011. Vol. 48. № 8. P. 1837-1856.

16. Moynihan D.P. Managing for Results in State Government: Evaluating a Decade of Reform // Public Administration Review. 2006. Vol. 66. № 1. P. 77-89. 